\title{
Interleukin - 6 Serum Level and Single Nucleotide Gene -174 G/C promoter Polymorphism in Patients with Rheumatoid Arthritis / Iraq
}

\author{
Ruba Ahmed Ibrahim AL-Khames Aga* , Firas Muhammed Al-Tae** \\ *Postgraduate Student, Department of Microbiology, College of Medicine , University of Mosul, \\ ${ }^{\star \star}$ Department of Microbiology, College of Medicine, University of Mosul, Mosul, Iraq \\ Correspondence: ruba.hmp25@student.uomosul.edu.iq
}

(Ann Coll Med Mosul 2021; 43 (2):164-175).

Received: $13^{\text {th }}$ Augu. 2021; Accepted: $12^{\text {th }}$ Octo. 2021.

\begin{abstract}
Objective: To 1) assess IL-6 levels in the serum of patients with rheumatoid arthritis (RA). 2) study IL-6 promoter -174 G>C "single nucleotide polymorphism (SNP)" as an imminent factor for the disease development. 3) find any relation between the level of serum IL-6 cytokine and other parameters such as age, gender, clinical severity of diseases and "disease activity scores (DAS28)".

Materials \& methods: This research was carried out through a case - control approach at "Ibn - Senna Teaching Hospital" in Mosul city between November 2020 and July 2021. It included 61 RA patients diagnosed according to "ACR / EULAR 2010 criteria" and 50 healthy individuals. IL-6 serum levels were ascertained by ELISA and genotyping of IL-6 promoter was accomplished by "sequence-specific primerpolymerase chain reaction (SSP-PCR)".

Results: Mean IL-6 level in RA (69.42 $\mathrm{ng} / \mathrm{I} \pm 62.99$ ) was elevated in comparison to healthy people (14.66 $\mathrm{ng}$ $/ I \pm 23.58), P<0.001$. No age or gender effects on IL-6 concentration were noted. The ideal cut-off of IL- 6 for discrimination of RA with best discriminative utility compared to healthy controls was $22.80 \mathrm{ng} / \mathrm{l}$. At this value the IL-6 sensitivity was $91.8 \%$, specificity $82.0 \%$ and accuracy rate $73.80 \%$. G/G genotype was the most pervasive genotype in both RA patients and controls (70.5\% in RA and $64 \%$ in healthy controls). However, it did not seem to be a risk factor for RA development compared to $\mathrm{G} / \mathrm{C}$ or $\mathrm{C} / \mathrm{C}$ genotypes "(OR $=1.3438,95 \%$ $\mathrm{Cl}=0.605-2.984, \mathrm{P}=0.469)$ ". The mean IL-6 level in patients with $\mathrm{GG}$ genotype was $(73.70 \mathrm{ng} / \mathrm{I} \pm 71.09)$ compared to $(58.37 \mathrm{ng} / \mathrm{I} \pm 37.86$ ) in patients with GC genotype. There was no significant difference in the IL-6 level between patients with $G G$ and patients with $G C$ genotypes $(P=0.2375)$. Although higher IL-6 mean concentration was reported in severe RA, however, no significant difference was found between patients with mild, moderate and severe RA respectively. No correlation of serum levels of IL-6 with genetic promoter polymorphism, clinical severity of diseases or DAS 28 score were reported.

Conclusion: The concentration of serum IL-6 was elevated in RA in regard to healthy controls which confirmed its pivotal role in RA pathogenesis. Our data did not support the role of IL-6 promoter -174 G>C polymorphism as a risk factor for RA, nor seem to play a major role in the increase of IL-6 level among our patients with RA.
\end{abstract}

Keywords: IL-6, rheumatoid arthritis, IL-6 genetic polymorphism, Iraq

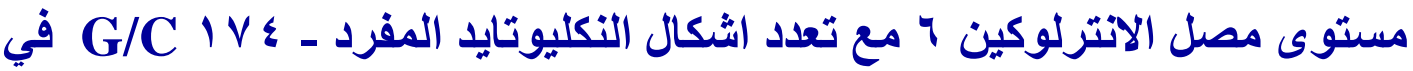

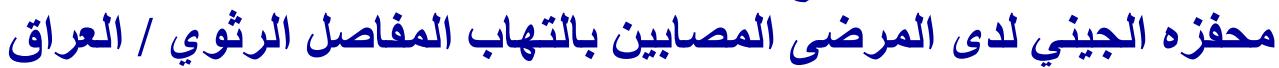

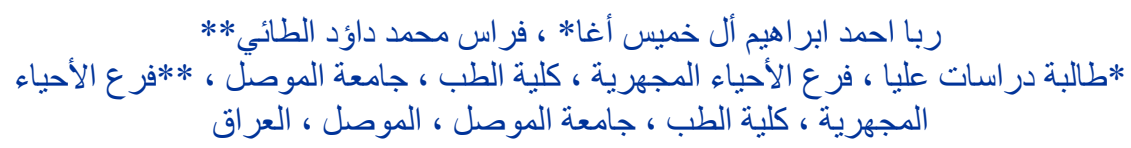

الاهداف : تقييم مستويات الانترلوكين السادس في امصال المرضى المصابين بالئ بالتهاب المفاصل الرثوي مع دراسة تعدد أثنكال

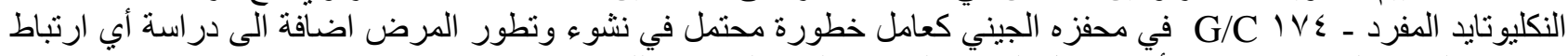

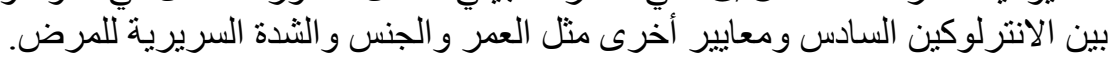


المواد وطرق العمل : هذه الدر اسة هي من نوع در اسات الحالات و الثو اهد وقد اجريت في مستشفى ابن سينا التعليمي في مدينة

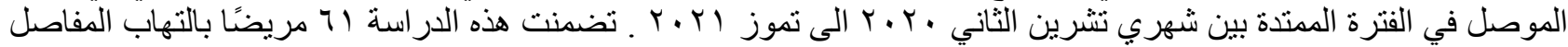

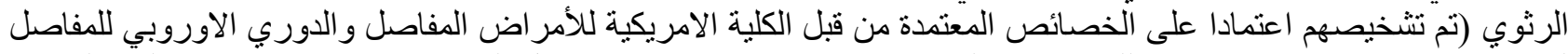

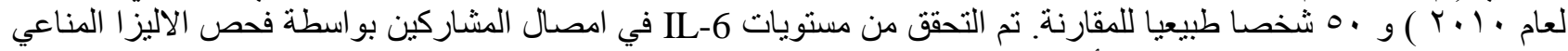
بينما تم الكثف عن تعدد أثكال النكليوتايد المفرد - ELISA)

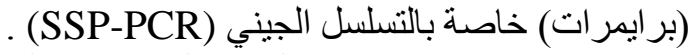

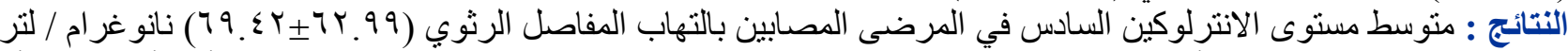

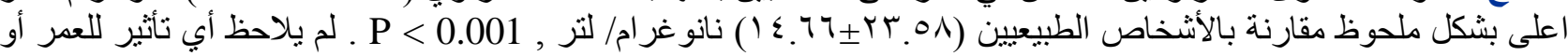

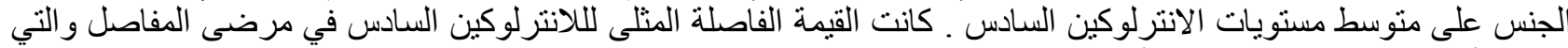

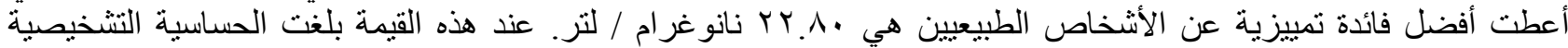

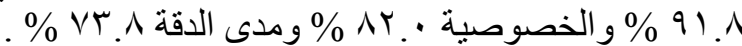

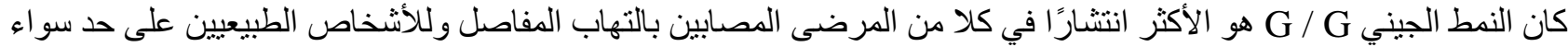

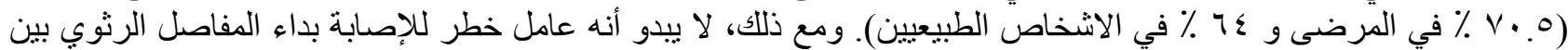

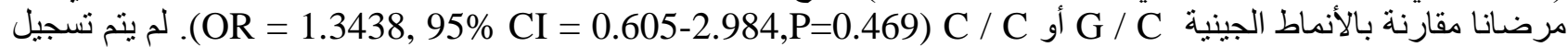

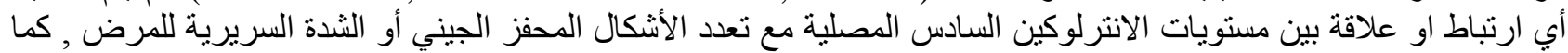

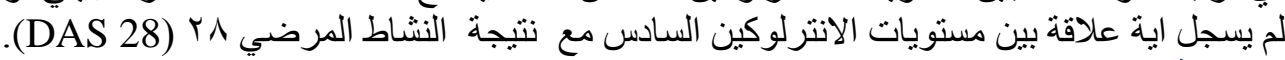

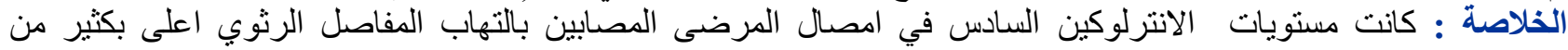

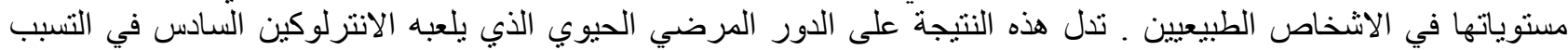

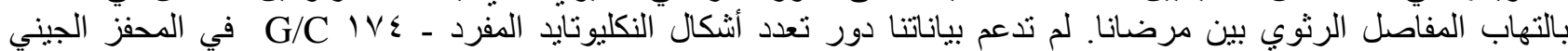

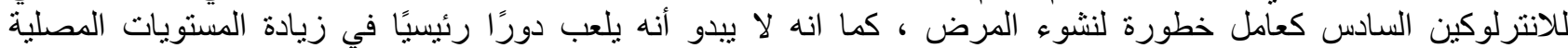
للانترلوكين السادس بين مرضنى التهاب المفاصل الرثوي.

الكلمات المفتاحية : الانترلوكين السادس ، داء المفاصل الرثوي ، تعدد اشكال النكليوتايد المفرد للانترلوكين السادس ، العراق .

\section{INTRODUCTION}

heumatoid arthritis (RA) is one of the autoimmune diseases that primarily affects small synovial joints causing synovitis, progressive cartilage destruction, bone loss, and joints deformities $^{1}$. A variety of manifestations outside the joints are also noticeable due to systematic immunological responses ${ }^{2}$. The exact cause of RA remains unascertained, however, various etiological factors including genetic, familial, hormonal, immunological, environmental and infectious variables have all been postulated ${ }^{3}$.

Interleukin-6 (IL-6) is a cytokine with diverse biological features that promote inflammation 4 . Several researches have clarified that the regulation of IL- 6 production is impaired in patients that complain of RA in both the synovial membranes and circulations ${ }^{5}$. In addition to protein disturbances, several genetic "single nucleotide polymorphisms (SNP)" in IL-6 promoter area or within IL-6 gene have been studied as possible risk targets.

Few studies in Iraq have addressed the role of IL6 cytokine in RA pathogenesis ${ }^{6-8}$. Among these studies only one study explore the effect of IL-6 promoter SNP at $-174 \mathrm{G}>\mathrm{C}$ position ${ }^{7}$. Therefore, the data about the IL- 6 cytokine (whether at protein or genetic levels) are still lacking among our patients. Therefore, the present study was conducted to achieve the following aims: 1) To investigate the serum concentrations of IL-6 in patients with RA in Mosul city and to compare them to healthy controls through a case - control study. 2) To detect SNP at -174 ( $\mathrm{G}>\mathrm{C}$ ) position" of IL-6 promoter area as a risk factor for diseases development. 3) To study any affiliation between IL-6 serum level and IL-6 -174 SNP and to report any correlation between IL- 6 level and other parameters such as age, gender, clinical severity of RA and DAS 28 scores.

\section{MATERIALS AND METHODS}

\section{Research Ethics}

This research was endorsed by the Council of College of Medicine / University of Mosul in November 2020 and by the "Ethical Committee of Nineveh Health Directorate (3/7/3124) " in December 2020. All individuals enrolled in this study gave written consent for participation.

\section{Subjects and Study Design}

The study was a "Case - Control" study and was carried out in the Department of Microbiology / College of Medicine / University of Mosul and private labs from November 2020 to July 2021. The study included 61 patients with RA who routinely visit Rheumatology clinics at Ibn - Sena 
Teaching Hospital. The diagnosis of RA was made according to "American College of Rheumatology European League Against Rheumatism (ACR / EULAR 2010) criteria" $^{9}$ and the assessment of severity of the diseases severity was done according to "Diseases Activity Score 28 (DAS 28)" criteria. The control group involved 50 apparently healthy individuals without any history of previous diseases. Exclusion criteria included subjects with other co-morbidities that might affect IL-6 level. These include for example other acute infections, other autoimmune diseases, liver diseases, thyroid diseases and pregnant women .

\section{METHODS}

\section{Blood sampling}

$5 \mathrm{ml}$ of human venous blood were collected from all RA and healthy individuals. After collection, $1 \mathrm{ml}$ of the blood from each sample was transferred immediately to another tube containing EDTA and frozen at $-20 \cong$ to be used later for DNA extraction. The remaining $4 \mathrm{ml}$ were centrifuged at $4000 \mathrm{rpm}$ within 1-2 hours for serum dissociation. The serum was frozen at $-20 \stackrel{\circ}{\circ}$ for quantification of IL- 6 by ELISA.

\section{IL-6 protein quantification by ELISA}

Human IL- 6 was determined in the serum using a quantitative human interleukin-6 sandwich 96 well ELISA kit (Cat. No E0090Hu, Bioassay Technology, China). This kit has a minimum sensitivity of $1.03 \mathrm{ng} / \mathrm{l}$.

\section{DNA extraction}

Whole blood genomic DNA from both patients and controls was extracted by "G-Spin ${ }^{\mathrm{TM}}$ Total DNA Extraction Mini Kit" (iNtRON Biotechnology, South Korea). The concentration of extracted DNA was determined by UV-Vis Spectrophotometer at $260 \mathrm{~nm}$ and the DNA integrity was confirmed by running on $0.7 \%$ agarose gel. The DNA samples were stored at $-20^{\circ} \mathrm{C}$ until used for "sequence specific primer - PCR (SSP - PCR).

\section{IL-6 promoter genotyping}

Ascertainment of -174 G $>C$ IL-6 promoter SNP was done by "SSP-PCR" using primer sequences obtained from published manuscripts ${ }^{10}$. Each PCR reaction included $\square 100 \mathrm{ng}$ of extracted DNA, $1 \mu \mathrm{l}$ of "Maxime ${ }^{T M}$ PCR PreMix Kit (i-Taq)" (iNtRONS Biotechnology, South Korea), $1 \mu \mathrm{l}$ equal to 10 pmole/ $\mu \mathrm{l}$ of IL-6 allele - specific forward primer, $1 \mu \mathrm{I}$ equal to $10 \mathrm{pmole} / \mu \mathrm{l}$ of IL-6 common reverse primer, $1 \mu \mathrm{l}(10 \mathrm{pmole} / \mu \mathrm{l})$ of $\mathrm{HGH}$ internal control forward primer and $1 \mu \mathrm{l}(10 \mathrm{pmole} / \mu \mathrm{l})$ of $\mathrm{HGH}$ reverse primer. The PCR volume was then completed to $20 \mu \mathrm{l}$ with distilled water. The PCR samples were placed into PCR thermocycler and the following parameters were used for amplification: 1 cycle of "initial denaturation" at 94 "C for $2 \mathrm{~min}$, repeated 35 cycles of "denaturation" at $94{ }^{\circ} \mathrm{C}$ for $20 \mathrm{sec}$, "annealing" at $60{ }^{\circ} \mathrm{C}$ for $10 \mathrm{sec}$ and "extension" at 72 for ${ }^{\circ} 30 \mathrm{sec}$ and then 1 cycle of "final extension" at $72{ }^{\circ} \mathrm{C}$ for $5 \mathrm{~min}$. The expected size of IL-6 promoter PCR product was $205 \mathrm{bp}$ and for HGH was 429 bp respectively.

\section{Statistical methods}

"Non-parametric Mann-Whitney test" was used to compare mean IL-6 concentrations between patients with RA and healthy individuals. "KruskallWallis" test" was utilized for inter-group comparison. "Area under the Receiver Operating Characteristics (AUC-ROC) curve" was employed to test the diagnostic validity of serum IL-6 at different cut-off values. For IL-6 gene polymorphism, the allele was counted by direct allele counting. "Chi-squared $\left(X^{2}\right)$ " test was applied to compare allele and genotype distribution. The "odds ratio $(\mathrm{OR})$ and $95 \%$ confidence intervals $(\mathrm{Cl}$ $95 \%$ )" were calculated to measure the relative risks in both controls and RA patients. DAS 28 online calculator (http://www.4s-dawn.com) was used to calculate DAS 28 score. Pearson Correlations coefficient was utilized to evaluate correlations between different parameters. Microsoft Excel 10 was used to construct figures and graphs. MedCalc® Statistical Software version 20 (Belgium) was a adopted to perform statistical analysis throughout this study.

\section{RESULTS}

Clinical, laboratory and demographic features of samples

This study included 61 patients who suffered from RA and 50 healthy people. The age of RA patients varied from $19-81$ years $(49.67 \pm 13.54)$ in comparison to $21-77$ years $(45.88 \pm 15.26)$ in healthy controls $(P=0.1538)$. Gender analysis revealed 52 females and 9 males participants among RA and 31 females and 19 males among healthy controls. RA was significantly more frequent among females than males among our population $(X 2=7.801, P=0.0052)$. In addition, 17 patients gave positive family for RA representing $(27.87 \%)$ of the total number of RA patients. Average DAS 28 score for patients with mild RA was $(3.11 \pm 0.01, n=5)$ versus $(4.66 \pm 0.40, n=$ $17)$ in moderate and $(6.81 \pm 0.45, n=39)$ in severe RA respectively.

\section{Serum IL-6 in RA and healthy individuals}

The arithmetic mean \pm SD of serum IL- 6 in RA was (69.42 $\mathrm{ng} / \mathrm{I} \pm 62.99$ ) in comparison to (14.66 $\mathrm{ng} / / \pm 23.58$ ) in healthy controls (Figure $1 \mathrm{~A}$ ). The 
serum IL-6 was significantly elevated in RA patients than in healthy individuals $(P<.001)$.

The results of gender effect on IL-6 level were shown in (Figure 1B). No statistical difference was found between RA females (72.54 $\pm 66.98, n=$ $52)$ and males (51.33 $\pm 26.91, n=9)(P=0.502)$. Nevertheless, IL-6 concentration was significantly increased in both females and males in all patients with RA in comparison to their sex - matched healthy controls $(P<.01)$.

Next, RA patients were categorized into different age groups to find if there is any particular age trend for RA and serum IL-6 protein. As indicated, RA was most frequently seen in the age groups between $46-55$ years $(n=22)$ followed by the age group of $36-45$ years $(n=15)$ (Figure $1 \mathrm{C})$. Regarding serum IL-6 protein level, the highest concentrations in age group $<25$ years $(125.44$ $\mathrm{ng} / \mathrm{l} \pm 112.19)$ and age group $26-35$ years (116.55 $\mathrm{ng} / \mathrm{l} \pm$ 98.71). However, no significant difference was found between all age groups in regard to IL-6 $(P=0.114)$.

Sensitivity and specificity of IL-6 at different cut-off values for the diagnosis of RA

Different cut-off value ranging from 0.9 to $377 \mathrm{ng} / \mathrm{l}$ were generated and examined (Table 1). For RA, the AUC-ROC was $0.867(95 \% \mathrm{Cl}: 0.792$ to 0.942). The AUC-ROC differed significantly from healthy people $(P<0.0001$, Figure 2$)$. This mean that the IL- 6 has an excellent ability to differentiate between RA and controls. The cut-off value which gave best combination of highest sensitivity $(91.8 \%)$, specificity $(82.0 \%),+\operatorname{LR}(5.10 \%)$ and LR $(0.100 \%)$ was $22.80 \mathrm{ng} / \mathrm{l}$ with an overall accuracy rate of $73.8 \%$ (Youden index $=0.7380$ ).

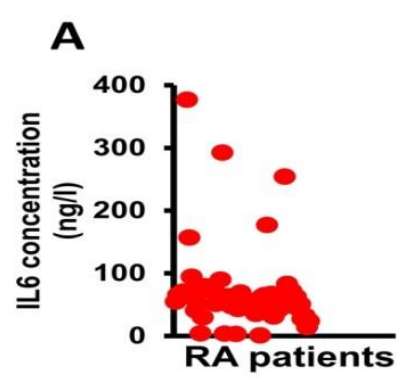

B
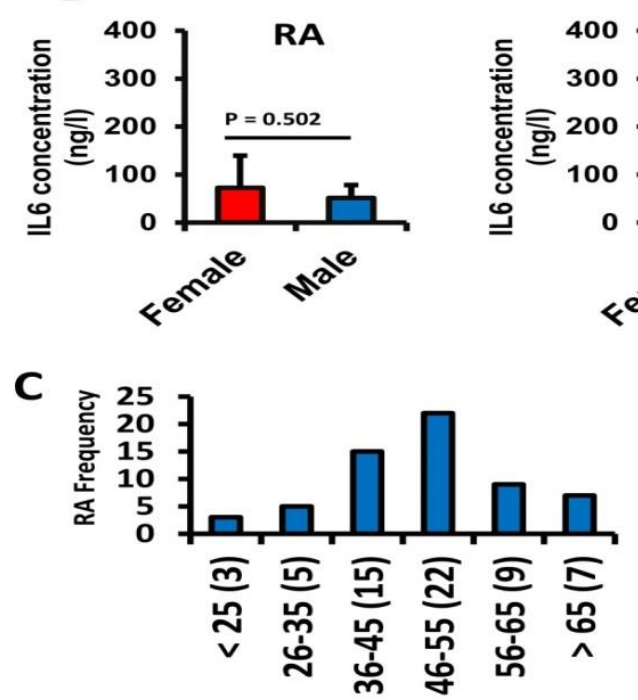
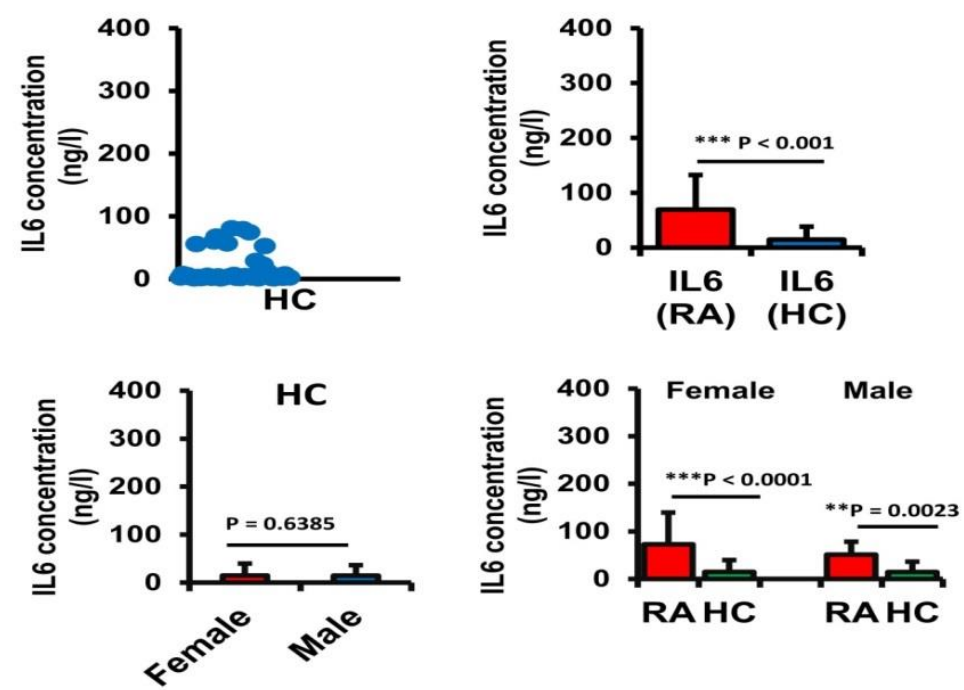

Figure 1: A) IL-6 serum concentrations in RA patients and healthy individuals. Mean IL-6 level in RA (69.42 $\mathrm{ng} / \mathrm{I} \pm 62.99, n=61)$ was significantly increased in comparison to healthy persons $(14.66 \mathrm{ng} / \mathrm{I} \pm 23.58, n=$ $50), P<0.001$, " Mann-Whitney test" was used for comparison B) IL-6 concentration in RA and healthy personals by gender. The mean IL-6 concentration in RA females $(72.54 \pm 66.98, n=52)$ did not seen significantly different compared to males population $(51.33 \pm 26.91, n=9),(P=0.502)$. C) Serum IL-6 level (ng/l) according to different age groups. IL-6 was not significantly different in various age groups $(P=0.114)$, "Kruskal - Wallis Test" was performed for comparison. Error bars represent SD. ${ }^{* *} \mathrm{P}<.01,{ }^{* * *} \mathrm{P}<.001$. 
Table 1: Diagnostic utility of serum IL-6 for the diagnosis of RA at different cut-off merits. The cut-off value of $22.8 \mathrm{ng} / \mathrm{l}$ gave the best combination of highest sensitivity $(91.8 \%)$, specificity $(82.0 \%),+\mathrm{LR}(5.10 \%)$ and - LR $(0.100 \%)$. The overall accuracy rate was $73.8 \%$ (Youden index $=0.7380$ ).

\begin{tabular}{|c|c|c|c|c|c|c|c|c|}
\hline Criterion & Sensitivity & $95 \% \mathrm{Cl}$ & Specificity & $95 \% \mathrm{Cl}$ & +LR & $95 \% \mathrm{Cl}$ & - LR & 95 \\
\hline$\geq 0.9080864$ & 100.00 & $94.1-100$ & 0.00 & $0.0-7.1$ & 1.00 & $1.0-1.0$ & & \\
\hline$>1.0384309$ & 100.00 & $94.1-100$ & 6.00 & $1.3-16.5$ & 1.06 & $1.0-1.1$ & 0.00 & \\
\hline$>1.2203972$ & 98.36 & $91.2-100$ & 6.00 & $1.3-16.5$ & 1.05 & $1.0-1.1$ & 0.27 & $0.03-2.5$ \\
\hline$>3.1024372$ & 98.36 & $91.2-100$ & 42.00 & $28.2-56.8$ & 1.70 & $1.3-2.2$ & 0.039 & $0.005-0.3$ \\
\hline$>3.2199000$ & 96.72 & $88.7-99.6$ & 42.00 & $28.2-56.8$ & 1.67 & $1.3-2.1$ & 0.078 & $0.02-0.3$ \\
\hline$>3.4014797$ & 96.72 & $88.7-99.6$ & 46.00 & $31.8-60.7$ & 1.79 & $1.4-2.3$ & 0.071 & $0.02-0.3$ \\
\hline$>3.7645424$ & 95.08 & $86.3-99.0$ & 48.00 & $33.7-62.6$ & 1.83 & $1.4-2.4$ & 0.10 & $0.03-0.3$ \\
\hline$>4.1274763$ & 93.44 & $84.1-98.2$ & 54.00 & $39.3-68.2$ & 2.03 & $1.5-2.8$ & 0.12 & $0.05-0.3$ \\
\hline$>12.013570$ & 93.44 & $84.1-98.2$ & 78.00 & $64.0-88.5$ & 4.25 & $2.5-7.2$ & 0.084 & $0.03-0.2$ \\
\hline$>14.402860$ & 91.80 & $81.9-97.3$ & 78.00 & $64.0-88.5$ & 4.17 & $2.5-7.1$ & 0.11 & $0.04-0.2$ \\
\hline$>22.808940$ & 91.80 & $81.9-97.3$ & 82.00 & $68.6-91.4$ & 5.10 & $2.8-9.3$ & 0.100 & $0.04-0.2$ \\
\hline$>27.707847$ & 88.52 & $77.8-95.3$ & 82.00 & $68.6-91.4$ & 4.92 & $2.7-8.9$ & 0.14 & $0.07-0.3$ \\
\hline$>28.792967$ & 88.52 & $77.8-95.3$ & 84.00 & $70.9-92.8$ & 5.53 & $2.9-10.5$ & 0.14 & $0.07-0.3$ \\
\hline$>51.940575$ & 60.66 & $47.3-72.9$ & 84.00 & $70.9-92.8$ & 3.79 & $1.9-7.4$ & 0.47 & $0.3-0.7$ \\
\hline$>52.693255$ & 60.66 & $47.3-72.9$ & 86.00 & $73.3-94.2$ & 4.33 & $2.1-8.9$ & 0.46 & $0.3-0.6$ \\
\hline$>55.044611$ & 59.02 & $45.7-71.4$ & 86.00 & $73.3-94.2$ & 4.22 & $2.1-8.6$ & 0.48 & $0.3-0.7$ \\
\hline$>55.904991$ & 59.02 & $45.7-71.4$ & 88.00 & $75.7-95.5$ & 4.92 & $2.3-10.7$ & 0.47 & $0.3-0.6$ \\
\hline$>56.248917$ & 54.10 & $40.8-66.9$ & 88.00 & $75.7-95.5$ & 4.51 & $2.1-9.9$ & 0.52 & $0.4-0.7$ \\
\hline$>56.764565$ & 54.10 & $40.8-66.9$ & 90.00 & $78.2-96.7$ & 5.41 & $2.3-12.8$ & 0.51 & $0.4-0.7$ \\
\hline$>59.167089$ & 49.18 & $36.1-62.3$ & 90.00 & $78.2-96.7$ & 4.92 & $2.1-11.7$ & 0.56 & $0.4-0.7$ \\
\hline$>59.681094$ & 49.18 & $36.1-62.3$ & 92.00 & $80.8-97.8$ & 6.15 & $2.3-16.3$ & 0.55 & $0.4-0.7$ \\
\hline$>67.016637$ & 29.51 & $18.5-42.6$ & 92.00 & $80.8-97.8$ & 3.69 & $1.3-10.2$ & 0.77 & $0.6-0.9$ \\
\hline$>67.865741$ & 29.51 & $18.5-42.6$ & 94.00 & $83.5-98.7$ & 4.92 & $1.5-15.7$ & 0.75 & $0.6-0.9$ \\
\hline$>73.280936$ & 19.67 & $10.6-31.8$ & 94.00 & $83.5-98.7$ & 3.28 & $1.0-11.0$ & 0.85 & $0.7-1.0$ \\
\hline$>74.629581$ & 18.03 & $9.4-30.0$ & 96.00 & $86.3-99.5$ & 4.51 & $1.0-19.4$ & 0.85 & $0.7-1.0$ \\
\hline$>77.656492$ & 14.75 & $7.0-26.2$ & 96.00 & $86.3-99.5$ & 3.69 & $0.8-16.3$ & 0.89 & $0.8-1.0$ \\
\hline$>79.668633$ & 13.11 & $5.8-24.2$ & 98.00 & $89.4-99.9$ & 6.56 & $0.8-50.7$ & 0.89 & $0.8-1.0$ \\
\hline$>80.672965$ & 13.11 & $5.8-24.2$ & 100.00 & $92.9-100$ & $92.9-100$ & & 0.87 & $0.8-1.0$ \\
\hline$>83.345511$ & 11.48 & $4.7-22.2$ & 100.00 & $92.9-100$ & & & 0.89 & $0.8-1.0$ \\
\hline$>89.990796$ & 9.84 & $3.7-20.2$ & 100.00 & $92.9-100$ & & & 0.90 & $0.8-1.0$ \\
\hline$>94.776395$ & 8.20 & $2.7-18.1$ & 100.00 & $92.9-100$ & & & 0.92 & $0.9-1.0$ \\
\hline$>157.10994$ & 6.56 & $1.8-15.9$ & 100.00 & $92.9-100$ & & & 0.93 & $0.9-1.0$ \\
\hline$>177.02244$ & 4.92 & $1.0-13.7$ & 100.00 & $92.9-100$ & & & 0.95 & $0.9-1.0$ \\
\hline$>254.48381$ & 3.28 & $0.4-11.3$ & 100.00 & $92.9-100$ & & & 0.97 & $0.9-1.0$ \\
\hline$>292.62301$ & 1.64 & $0.04-8.8$ & 100.00 & $92.9-100$ & & & 0.98 & $1.0-1.0$ \\
\hline$>377.14000$ & 0.00 & $0.0-5.9$ & 100.00 & $92.9-100$ & $92.9-100$ & & 1.00 & $1.0-1.0$ \\
\hline
\end{tabular}

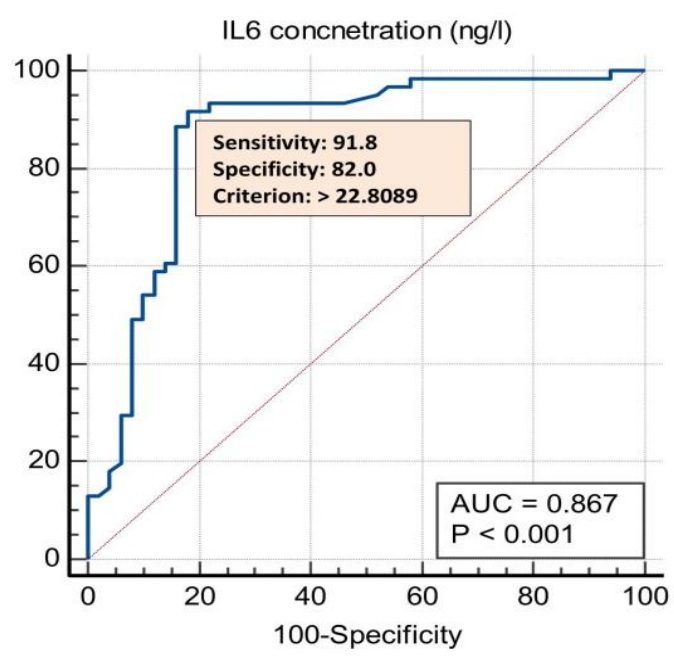

Figure 2: "AUC -ROC" curve of serum IL-6 for RA discrimination. The optimal cut-off value which gave best discriminative utility and highest combination of sensitivity and specificity was $22.80 \mathrm{ng} / \mathrm{l}$.

Frequencies of different "IL-6 promoter -174 G>C" genotypes and alleles

DNA was successfully extracted from all RA and healthy individuals (Figure $3 A$ ). The extracted DNA was used as a template for SSP-PCR for "IL-6 promoter -174 (G>C) SNP". Examples for the results of SSP-PCR for IL-6 genotyping and their interpretation were shown in (Figure 3B). Genotyping analysis showed that the $-174 \mathrm{G} / \mathrm{G}$ genotype was prevailed in both RA and controls (70.5\%, $n=43$ in RA and $64 \%, n=32$ in healthy controls) (Table 2). Our results did not support the role of IL-6 promoter $-174 \mathrm{G} / \mathrm{G}$ genotype as a risk factor for RA since the frequency did not statistically differ from healthy controls $(X 2=0.524$, $\mathrm{P}=0.4693) . \mathrm{G} / \mathrm{C}$ genotype was more prevailing in healthy controls $(36 \%, n=18)$ than in patients with RA $(27.9 \%, n=17),(\mathrm{OR}=0.7028, \mathrm{Cl}=0.314$ 1.573). However, its role as a protective factor in RA is a matter of debate since no significant distinction was found between the two groups. C/C genotype was the least frequent genotype reported in both groups (1.6\% and $0 \%$ respectively). Regarding allele frequencies, $-174 \mathrm{G}$ allele was the most prevalent allele in both groups and its frequency was comparable in both RA cases and healthy subjects $[103(84.4 \%), \mathrm{OR}=1.190, \mathrm{Cl}=$ $0.586-2.413)$ in RA compared to $82(82.0 \%)$, OR $=0.840, \mathrm{Cl}=0.414-1.704)$ in healthy controls]. No significant variance was found in allele frequencies between RA people and healthy individuals $(\mathrm{X} 2=$ $0.232, P=0.6301)$. 
IL-6 serum level according to "-174 (G/C) SNP IL-6 mean levels in RA and healthy individuals were compared according to $-174(\mathrm{G}>\mathrm{C})$ SNP to address the influence of IL- 6 genetic polymorphism on IL-6 serum protein level. The results were summarized in (Figure 4). The mean IL-6 level in RA patients with GG genotype was $(73.70 \mathrm{ng} / \mathrm{I} \pm$ $71.09, n=43)$ compared to $(58.37 \mathrm{ng} / \mathrm{I} \pm 37.86, n$ $=17$ ) in patients with GC genotype. Unfortunately, only one patient with CC genotype had been reported in this study with IL-6 level of $73.28 \mathrm{ng} / \mathrm{l}$.
No significant difference in the IL-6 level between RA patients with $G G$ and $G C$ genotypes $(P=$ $0.2375)$. Similarly, in healthy individuals the mean IL-6 concentration did not differ significantly between individuals with GG (14.55 $\pm 22.99, n=$ $32)$ and $\mathrm{GC}(14.86 \pm 25.25, n=18)$ genotypes $(\mathrm{P}=$ $0.4129)$. However, comparison of IL-6 mean level in each genotype group to their matched- genotype groups in healthy controls revealed a highly significant difference $(P<0.0001)$.

\section{A}

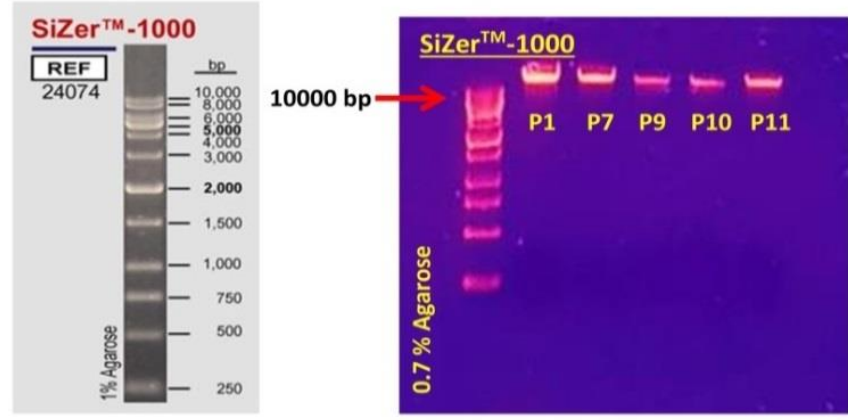

B

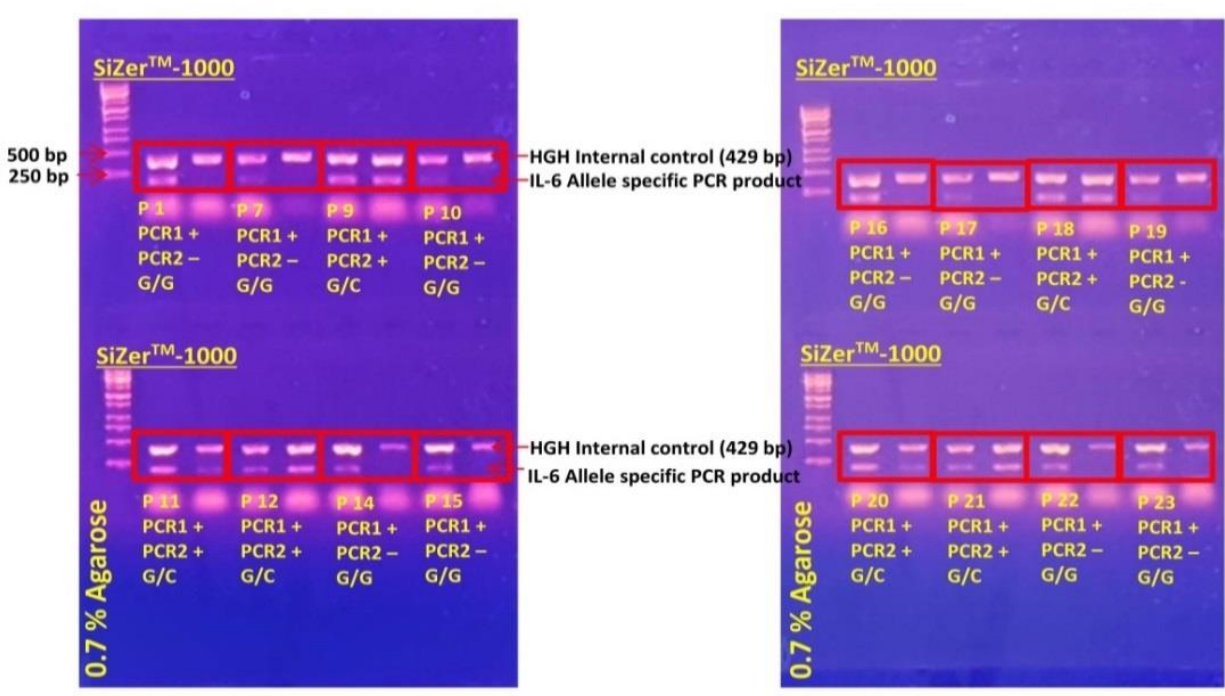

Figure 3: A) Human genomic DNA extraction from the blood of RA patients. DNA was extracted from $200 \mu$ of human blood by "spin column technology". $5 \mu \mathrm{l}$ of the extracted DNA from each sample was then loaded on $0.7 \%$ agarose gel to be checked for its quality by gel electrophoresis. The size of the extracted genomic DNA was larger than $10000 \mathrm{pb}(10 \mathrm{kbp})$ as indicated by the accompanied DNA ladder. B) Agarose electrophoresis of IL-6 promoter "-174 G/C genotyping". Extracted human genomic DNA was used as a template for $-174 \mathrm{G} / \mathrm{C}$ genotyping. For each patient and healthy control, two PCR reaction were set, one for the detection of $-174 \mathrm{G}$ allele and other for the detection of $-174 \mathrm{C}$ allele together with $\mathrm{HGH}$ internal control. Note the size of the HGH PCR product was $429 \mathrm{bp}$ while the size of allele specific IL-6 PCR product was 205 bp. Sizer TM 1000 DNA ladder ( from 250 bp to 10000 bp) was used to compare the sizes of HGH and IL-6 product. 
Table 2: Genotype and allele frequencies of "-174 G>C of IL-6 promoter SNP" in RA and controls. "G/G genotype" and "G allele" were most frequent in both groups. The distribution of these genotype and allele were $\approx 1$ - 1.3 fold higher in RA. However, they did not seem to be a risk factor for RA. "Chi - squared test $X 2$ " was used to compare the frequency distribution between the two groups. Significant difference at $p \leq$ 0.05 .

\begin{tabular}{|c|c|c|c|c|}
\hline IL-6 promoter -174 G/C SNP & RA patients & $\begin{array}{l}\text { Healthy } \\
\text { Controls }\end{array}$ & OR (CI 95\%) & P value \\
\hline Genotype frequency & $\mathrm{N}=61$ & $\mathrm{~N}=\mathbf{5 0}$ & & \\
\hline G/G* & $43(70.5 \%)$ & $32(64.0 \%)$ & $1.3438(0.605-2.984)$ & $P=0.469$ \\
\hline $\mathbf{G} / \mathbf{C}^{* *}$ & $17(27.9 \%)$ & $18(36 \%)$ & $0.703(0.314-1.573)$ & \\
\hline $\mathrm{C} / \mathrm{C}$ & $1(1.6 \%)$ & $\mathbf{0}$ & $2.4545(0.098-61.595)$ & \\
\hline \multicolumn{5}{|l|}{ Allele frequency } \\
\hline $\mathbf{G}$ & $103(84.4 \%)$ & $82(82.0 \%)$ & $1.190(0.586-2.413)$ & $P=0.6301$ \\
\hline $\mathbf{C}$ & $19(15.6 \%)$ & $18(18.0 \%)$ & $0.840(0.414-1.704)$ & \\
\hline
\end{tabular}

* OR was calculated using $G / G$ as a risk factor and $G / C+C / C$ as the referent

${ }^{* *}$ OR was calculated using $\mathrm{G} / \mathrm{C}$ as a risk factor and $\mathrm{G} / \mathrm{G}+\mathrm{C} / \mathrm{C}$ as the referent

*** $\mathrm{OR}$ was calculated using $\mathrm{C} / \mathrm{C}$ as a risk factor and $\mathrm{G} / \mathrm{G}+\mathrm{G} / \mathrm{C}$ as the referent

RA

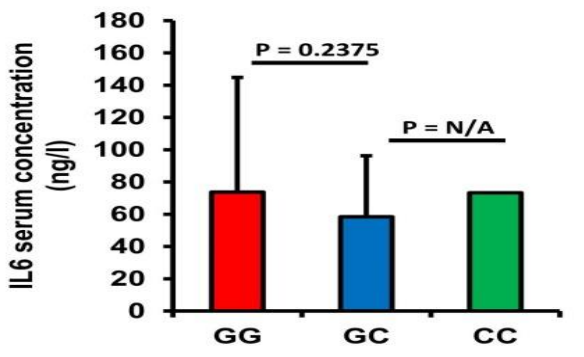

HC

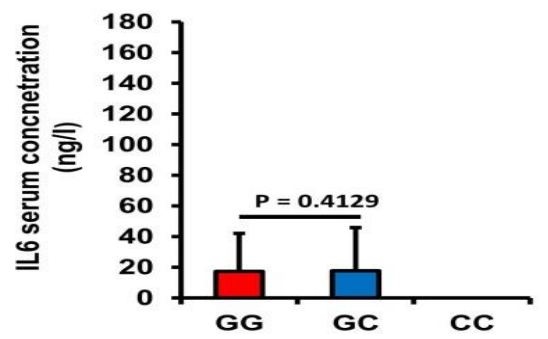

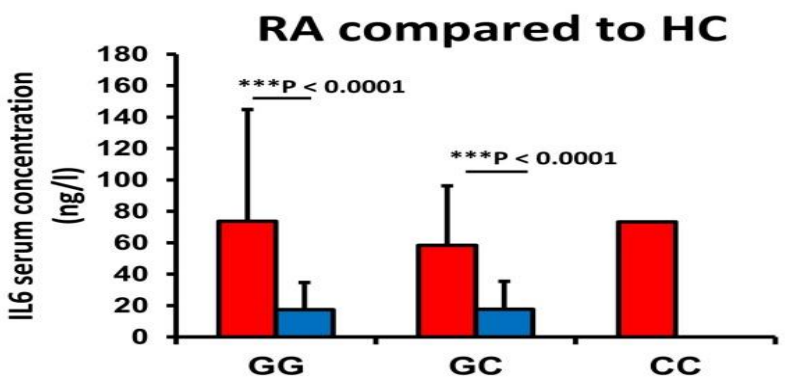

Figure 4: IL-6 mean concentration according to - $174 \mathrm{G} / \mathrm{C}$ promoter SNP. No statistical difference was found between IL- 6 serum level in RA patients with GG genotype $(73.70 \mathrm{ng} / \mathrm{I} \pm 71.09, n=43)$ and GC genotypes (58.37 ng /I \pm 37.86, $n=17$ ), P> 0.05 . "Mann-Whitney test" was utilized for comparison. Error bars represented SD.

\section{Correlation of IL- 6 with the severity of RA and DAS 28 scores}

The degree of severity was categorized into mild (DAS28 score $\leq 3.2$ ), moderate (DAS28 score3.2 to $\leq 5.1$ ) and severe (DAS28 score > 5.1). Accordingly, 5 cases were classified as mild, 17 were moderate and 39 cases were severe. The mean IL-6 concentration in mild RA was (49.67 ng/l \pm 17.33$)$ in comparison to (55.76 $\mathrm{ng} / \mathrm{l} \pm 24.00)$ in moderate RA and $(77.91 \mathrm{ng} / \mathrm{l} \pm 76.04)$ in severe RA. No statistical difference was established among all three groups $(P>0.05)$ (Figure $5 A)$. To reach a better conclusion on the association of IL-6 serum concentration to RA disease, Pearson correlation coefficient was employed to test whether IL-6 
correlated with DAS 28 criteria and clinical severity of the disease. In support of the above results, there was no correlation between overall IL-6 level and overall DAS 28 score $(r=0.1145, \mathrm{P}=0.3796$; Figure 5B). Nevertheless, IL-6 could not predict the clinical course in any of the three studied groups $(P>0.05)$.

\section{DISCUSSION}

The current study indicated that serum IL-6 was significantly increased in RA in comparison to healthy people. These findings were consistent with some other studies in Iraq ${ }^{6-8}$, middle east ${ }^{11,12}$ and worldwide ${ }^{13-}$ ${ }^{15}$. Overall, these results extended our previous mastery and came to clarify the principal role of IL- 6 in RA pathogenesis. In this context, dysregulation of IL-6 synthesis both at gene and protein level as a result of immune system disturbances, tissue damage or infection in genetically predisposed individuals might all be proposed as possible mechanisms for this increase.

Our results also confirmed that serum IL-6 level was increased in RA in a manner that was independent of patient gender. Mun and colleague, 2020 showed that women have substantial IL- 6 reactivity than men when exhibited to acute pain in vitro ${ }^{16}$. They supposed that this reactivity may "contribute to the maintenance and/or exacerbation of knee osteoarthritis". In contrast, other researchers could not find such association between IL-6 level and gender in diseases like RA ${ }^{11,17,18}$. Moreover, controversy was also noted regarding the direction of gender predominance of IL-6 in different diseases. For instance, Mun et al, $2020^{16}$ and O'Connor et al, $2007{ }^{19}$ found female predominance while Sperry et al, $2008{ }^{20}$ suggested male predominance in IL-6 expression following severe injury. In these settings, nature of diseases studied, hormonal differences, sample size, methodological approaches, study settings and population characteristics all can be contributing factors.

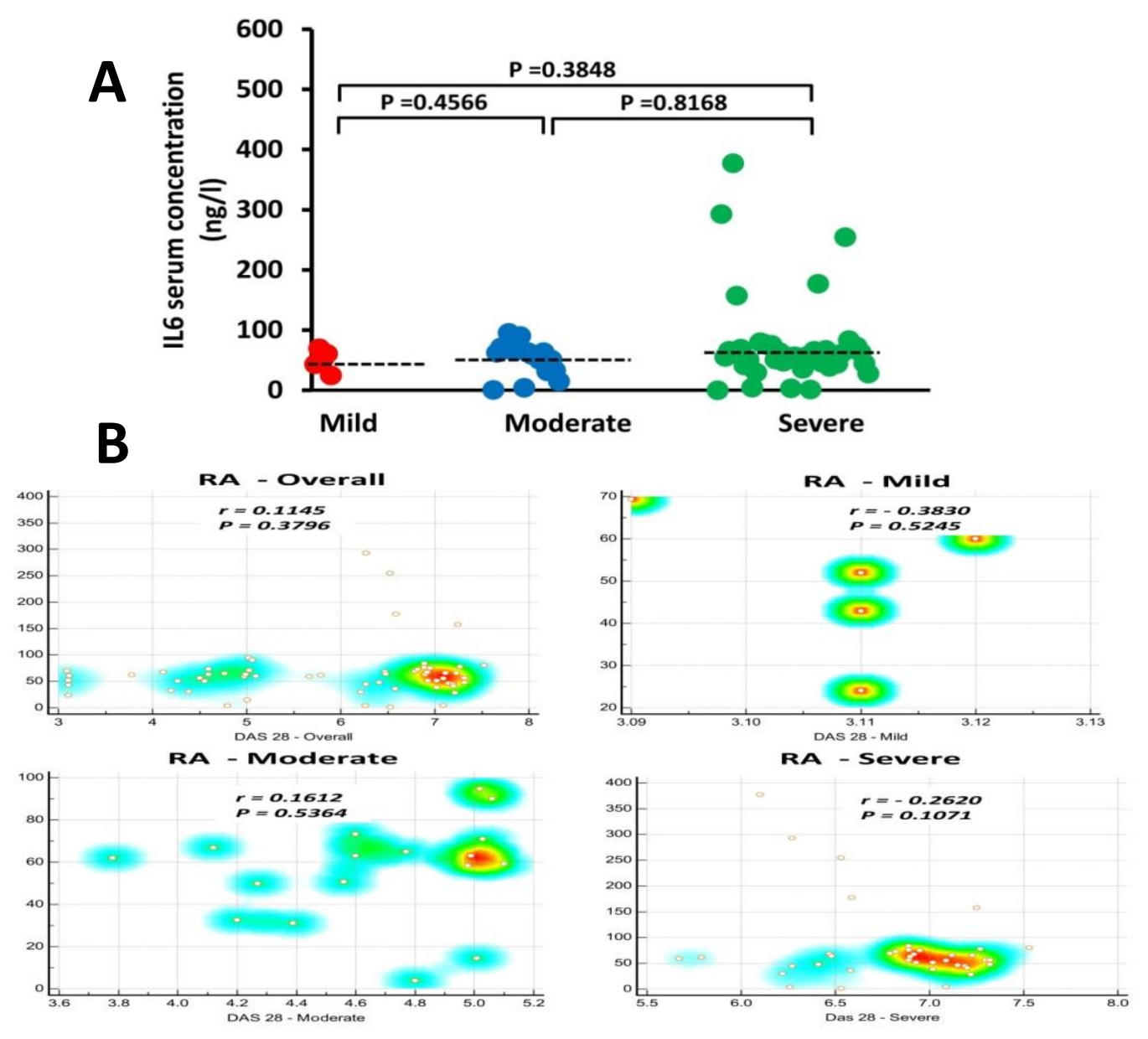

Figure 5: A) IL-6 concentration did not seem different between mild, moderate and severe RA ( $P>0.05)$. Dash lines represented the mean IL-6 concentration in each group. B) Correlation of serum concentrations of IL-6 cytokine with DAS 28 criteria. Overall, no correlation between IL-6 level and DAS 28 criteria $(r=0.1145$, $P=0.3796) . r=$ Pearson correlation co-efficient. Significant level at $P<0.05$. 
The result of the current study did not support a significant connection between IL- 6 and aging in RA patients. Although many studies in literature support an age-related increment in IL-6 concentration ${ }^{21-27}$, several factors might influence this association. These include the sample size, nature of study population (whether healthy or diseased people), the presence or absence of inflammation (with a tendency toward increase IL-6 concentrations in elderly people with high CRP levels), differential prevalence of IL- 6 gene polymorphism, age range studied, and the gender of the studied population. When considering these factors altogether support the idea that the increase in IL-6 level with age seen in these studies might not be primarily due to the aging process alone. In support to above suggestion, other researches did not find such association whether in healthy individuals ${ }^{28}$ or patients with RA ${ }^{11,17,18}$. However, because of the conflict findings, understanding the influence of age on serum levels of IL-6 especially in RA requires further investigation.

There is no a universal cut-off for the IL-6 in the diagnosis of different diseases, nor an optimal value for normal concentration since its level is raised only transiently and this increase is influenced by several factors. A meta-analysis study included 140 different research found that the average concentration of IL- 6 in the majority of healthy people ranged between 4.631 and 5.740 $\mathrm{pg} / \mathrm{ml}(\mathrm{ng} / \mathrm{l})^{29}$. These variation might be attributed to differences in the weight of these people and their muscle mass and contractility status ${ }^{29}$. Accordingly, we tried to examine the cut-of value of $>4.1 \mathrm{ng} / \mathrm{l}$ as a discriminative cut-off between healthy population and RA patients in our cohort. Here, we found that this value had a sensitivity of $93.44 \%$ and a specificity of only $54.00 \%$. These results necessitated the search for other cut-off values to optimize the validity of IL-6 in predicting the diagnosis of RA. In this context, several cut-off values were examined in this study by AUC-ROC curve analysis, ranging from $0.9-377 \mathrm{ng} / \mathrm{l}$ (Table 2). We observed that the ideal cut-off value of IL-6 for predicting RA was $22.8 \mathrm{ng} / \mathrm{l}(91.8 \%$ sensitivity, $82.0 \%$ specificity). Comparing with other study in Iraq, Abdullah et al, $2013{ }^{6}$ reported an optimum cut-off value of $8.1 \mathrm{pg} / \mathrm{ml} \mathrm{(ng/l)} \mathrm{with} 100.0 \%$ sensitivity and $34.8 \%$ specificity. Another study carried out in Iran ${ }^{12}$ found that at a cut - off value of 4.08 , the IL- 6 had a sensitivity of $93.33 \%$ and a specificity of $73.33 \%$ for the diagnosis of RA. However, it is worthy to mention that IL-6 is a nonspecific marker that can be elevated in different physiological and pathological circumstances and therefore should not be utilized as a sole marker for the diagnosis of disease.

In the current research, $G / G$ genotypes were more prevalent in both RA and healthy controls. $70.5 \%$ of RA patients were with IL- 6 promoter G/G genotype, $27.9 \%$ with G/C genotype, and only $1.6 \%$ with $\mathrm{C} / \mathrm{C}$ genotypes in comparison to $64.0 \%$ $\mathrm{G} / \mathrm{G}, 36 \% \mathrm{G} / \mathrm{C}$ and $0 \% \mathrm{C} / \mathrm{C}$ among the healthy population. No significant difference has been recorded in the genotype and allele frequencies at - 174 position of IL-6 promoter between RA and healthy subjects. Hence, these results could not encourage the role of IL- 6 promoter polymorphism at -174 position as a risk factor for the development of RA among our patients in Mosul city. A study in Egypt ${ }^{11}$ showed that " $64.86 \%$ of patients with RA were with IL-6 promoter -174 $\mathrm{G} / \mathrm{G}, 29.73 \%$ with $\mathrm{G} / \mathrm{C}$ and $5.41 \%$ with $\mathrm{C} / \mathrm{C}$ genotype, while $90 \%$ of the control group showed G/G genotype". However, in contrast to our study, they found that the distribution of different genotypes and alleles at position -174 of IL- 6 promoter were significantly different between RA individuals and healthy populations. They concluded that GG genotype might be a risk factor for the development of RA. Similarly, another study carried out in Guangdong, China ${ }^{30}$ revealed a significant difference in the frequencies of IL-6 promoter polymorphism at -174 position between RA and healthy people. A Spanish study ${ }^{31}$ showed no significant difference in distribution of different IL-6 promoter genotypes and alleles at position 174 between RA patients and healthy controls and thus they denied any association between IL- 6 promoter polymorphism and susceptibility to RA. In this setting, most studies that reported a significant association between IL-6 promoter polymorphism and RA were carried out on the Asian and Middle East ethnic population ${ }^{32}$. On other hand, most studies that ruled out this association were carried out on European populations ${ }^{32}$. However, this conclusion is not being encouraged in Iraq. In a study in Babylon Province ${ }^{7}$ found that " $80 \%$ of patients with RA had IL-6 GG genotype, $18.3 \%$ 
with GC and $1.6 \%$ with $\mathrm{CC}$, while $98 \%$ of the control showed GG genotype with $1.6 \%$ with GC". Although the percentages of $G G$ and $G C$ genotypes in healthy controls in this study were higher than our study, but they agreed with our finding in respect to the lack of genetic association between (-174 G>C) IL-6 promoter polymorphism and susceptibility to RA. We also could not find any significant difference in the mean IL-6 concentration between patients with $G G$ and $G C$ genotypes $(P=0.2375)$. Some studies had concluded that IL- 6 was higher in RA patients with CC genotypes in comparison to those with $G G$ and GC genotypes ${ }^{11}$. In contrast, other studies were found that $C$ allele at -174 position results in a reduction in expression strength of IL- 6 promoter and hence lower IL- 6 serum levels were found in patients with the CC genotype compared with GC or GG patients ${ }^{31}$. Meanwhile, other researchers did not find any definite association between IL- 6 promoter polymorphisms at -174 position and IL-6 serum levels ${ }^{33,34}$. Similarly, the result of the current study did not confer an effect of IL-6 -174 $\mathrm{G}>\mathrm{C}$ promoter polymorphism on IL-6 serum level. Based on these results, we thought that the increase in IL-6 concentration noticed in patients with RA might not be, at least in part, genetically determined, and other factors other than genetics might be more important in this issue. We suggested that the induction and increase concentration of IL- 6 in both the sera and the joint fluids of RA patients are due to a plethora of cumulative effects of various chemical, physiological and immunological compounds including inflammatory cytokines such as TNFalpha and $\mathrm{IL}-1$ rather than simply attributed to genetic differences in IL-6 promoter.

We sought to investigate whether the elevated IL6 in RA was correlated with increased disease activity as indicated by DAS 28 score and ESR level and therefore if the IL-6 could be used as an indicator of disease activity among our patients. The results of the present study indicated no significant difference among mild, moderate and severe diseases $(P>0.05)$. Moreover, IL-6 did not correlate with DAS 28 criteria among our studied patients $(r=0.1145, \mathrm{P}=0.3796)$. Despite these results, failure to demonstrate such correlation in our opinion should not necessarily trivialize the role and importance of IL-6 in disease activity. In this context, the absence of a direct relationship between IL- 6 and DAS 28 scores does not always reflect the actual contribution of IL- 6 to the disease process. Helal et al, $2012{ }^{17}$ \& Chung et al, $2011^{35}$ failed to report a direct correlation between the IL-6 and DAS 28 scores, however, they had shown that the IL-6 was correlated with other markers of illness activity such as $\mathrm{ESR}^{17}$ and $\mathrm{CRP}^{35}$ respectively. In addition, the same researchers explained the lack of relationship between the serum IL-6 level and DAS 28 scores in their studies on the basis of the differences in the implication of the IL- 6 family cytokines in the local (synovium) and systemic circulation (serum). Thus the concentration of IL-6 family of cytokine was observed to be higher in the synovium more than the circulation ${ }^{35}$. Moreover, some components of DAS 28 scoring system such as the number of tender and swelling joints as well as the overall health condition of the patients are subjective components and are largely subjected to the personal judgement of the physicians. Furthermore, apart from the differences in the sample sizes (which might in part explain the lack of consistency seen in different studies), in the current study we did not take into consideration the influence of the drugs on the IL- 6 which might be one of the limitations of this study.

\section{CONCLUSIONS}

This study showed that IL-6 concentration was significantly elevated in the sera of patients suffering from RA in comparison to healthy individuals. The optimum cut-off value for IL-6 which provides the best discriminative accuracy and best combination of highest sensitivity, specificity, +LR and -LR for RA among our patients was $22 \mathrm{ng} / \mathrm{l}$. At this value the sensitivity of IL-6 was $91.8 \%$, specificity of $82.0 \%$, +LR of 5.1 , and LR of 0.100 respectively. We could not find any particular age trend or gender difference between males and females in regard to IL-6 concentration in RA patients. We did not also report a significant correlation between IL- 6 and DAS 28 criteria, ESR or clinical severity of the disease. IL-6 promoter GG genotype at -174 position was more prevalent in both RA patients and healthy population. However, our data did not support the role of IL-6 promoter $-174 \mathrm{G}>\mathrm{C}$ polymorphism as a risk factor for the development of RA, nor seem to play a major role in the increase of IL-6 level among RA patients. 


\section{Acknowledgement}

We would like to thank the " Department of Microbiology " and the "Deanship of the College of Medicine / University of Mosul " for their constant support. We would also like to thank all patients and the staff of "Rheumatology Unit" at Ibn-Sena teaching hospital for their valuable help.

\section{Conflict of Interest}

The authors have no conflict of interest to declare.

\section{REFERENCES}

1.Bullock J, Rizvi SA, Saleh AM, Ahmed SS, Do DP, Ansari RA, et al. Rheumatoid arthritis: a brief overview of the treatment. Medical Principles and Practice. 2018;27(6):501-507.

2.Conforti A, Di Cola I, Pavlych V, Ruscitti P, Berardicurti $O$, Ursini $F$, et al. Beyond the joints, the extra-articular manifestations in rheumatoid arthritis. Autoimmun Rev. 2021;20(2):102735.

3. Deane KD, Demoruelle MK, Kelmenson LB, Kuhn KA, Norris JM, Holers VM, et al. Genetic and environmental risk factors for rheumatoid arthritis. Best Pract Res Clin Rheumatol. 2017;31(1):3-18.

4. Rose-john S. Interleukin-6 family cytokines. Cold Spring Harbor perspectives in biology. 2018;10(2):a028415.

5. Hashizume M, Mihara $M$. The roles of interleukin- 6 in the pathogenesis of rheumatoid arthritis. Arthritis. 2011.

6. Abdullah RM, Khalil AA, Jassim NA, Gorial FI. Serum IL17 and IL6 levels in a Sample of Iraqi Patients with Rheumatoid Arthritis: A Case Control Study. Chemistry and Materials Research. 2013;3(8).

7. Alta'ee AH, Alrubiae S. Serum Interleukin-6 and Gene Polymorphisms in Rheumatoid Arthritis Patients in Babylon Province, Iraq. International Journal of ChemTech Research. 2017,10(2): 662-669

8. Ali ET, Jabbar AS, Mohammed AN. A Comparative Study of Interleukin 6, Inflammatory Markers, Ferritin, and Hematological Profile in Rheumatoid Arthritis Patients with Anemia of Chronic Disease and Iron Deficiency Anemia. Anemia. 2019; 1;2019:3457347.

9. Aletaha D, Neogi T, Silman AJ, Funovits J, Felson DT, Bingham III CO, et al. Rheumatoid arthritis classification criteria: an American College of Rheumatology/European League Against Rheumatism collaborative initiative. Arthritis \& rheumatism. 2010 Sep;62(9):2569-81.

10. Attar M, Mansoori M, Shahbazi M. Interleukin6 genetic variation and susceptibility to gastric cancer in an Iranian population. Asian Pacific journal of cancer prevention. 2017;18(11):3025.

11. Gaber W, Azkalany GS, Gheita TA, Mohey A, Sabry R. Clinical significance of serum interleukin-6 and- 174 G/C promoter polymorphism in Rheumatoid arthritis patients. The Egyptian Rheumatologist. 2013; 1;35(2):107-13.

12. Rajaei E, Mowla K, Hayati Q, Ghorbani A, Dargahi-Malamir M, Hesam S, et al. Evaluating the Relationship Between Serum Level of Interleukin-6 and Rheumatoid Arthritis Severity and Disease Activity. Curr Rheumatol Rev. 2020;16(3):249-255.

13. Houssiau FA, Devogelaer JP, Damme JV, Deuxchaisnes CN, Snick JVI. Interleukin-6 in synovial fluid and serum of patients with rheumatoid arthritis and other inflammatory arthritides. Arthritis Rheum. 1988; 31 6:784-788.

14. Bhardwaj N, Santhanam U, Lau LL, Tatter SB, Ghrayeb J, Rivelis M, et al. IL-6/IFN-beta 2 in synovial effusions of patients with rheumatoid arthritis and other arthritides. Identification of several isoforms and studies of cellular sources. J Immunol (Baltimore, MD: 1950) 1989; 143 7:2153-2159.

15. Holte I, CooperR G, HopkinsS J. Relationships between local inflammation, interleukin-6 concentration and the acute phase response in arthritis patients. EurJ Clin Invest. 1991; 21: 47984.

16. Mun CJ, Letzen JE, Nance S, Smith MT, Khanuja HS, Sterling RS, et al. Sex differences in interleukin-6 responses over time following laboratory pain testing among patients with knee osteoarthritis. The Journal of Pain. 2020;21(56):731-41.

17. Helal AM, Shahine EM, Hassan MM, Hashad DI, Moneim RA. Fatigue in rheumatoid arthritis and its relation to interleukin- 6 serum level. The Egyptian Rheumatologist. 2012 1;34(4):153-7.

18. Madhok R, Crilly A, Watson J, Capell HA.. Serum interleukin 6 levels in rheumatoid arthritis: correlations with clinical and laboratory indices of disease activity. Ann Rheum Dis. 1993;52(3):232-4.

19. O'Connor MF, Motivala SJ, Valladares EM, Olmstead R, Irwin MR. Sex differences in monocyte expression of IL-6: role of autonomic mechanisms. American Journal of PhysiologyRegulatory, Integrative and Comparative Physiology. 2007;293(1):R145-51.

20. Sperry JL, Friese RS, Frankel HL, West MA, Cuschieri J, Moore EE, et al. Male gender is associated with excessive IL-6 expression following severe injury. $J$ Trauma. 2008;64(3):572-8. 
21. Wei J, Xu H, Davies JL, Hemmings GP. Increase of plasma IL-6 concentration with age in healthy subjects. Life sciences. 1992;51(25):1953-6.

22. Ershler WB, Sun WH, Binkley N, Gravenstein S, Volk MJ, Kamoske G, et al. Interleukin-6 and aging: blood levels and mononuclear cell production increase with advancing age and in vitro production is modifiable by dietary restriction. Lymphokine and cytokine research. 1993;12(4):225-30.

23. Hager K, Machein U, Krieger S, Platt D, Seefried G, Bauer J. Interleukin-6 and selected plasma proteins in healthy persons of different ages. Neurobiology of aging. 1994;15(6):771-2.

24. Kania DM, Binkley N, Checovich M, Havighurst $\mathrm{T}$, Schilling $\mathrm{M}$, Ershler WB. Elevated plasma levels of interleukin- 6 in postmenopausal women do not correlate with bone density. Journal of the American Geriatrics Society. 1995;43(3):236-9.

25. Cohen HJ, Pieper CF, Harris T, Rao KM, Currie MS. The association of plasma IL- 6 levels with functional disability in community-dwelling elderly. The Journals of Gerontology Series A: Biological Sciences and Medical Sciences. 1997;52(4):M201-8.

26. Harris TB, Ferrucci L, Tracy RP, Corti MC, Wacholder S, Ettinger Jr WH, et al. Associations of elevated interleukin- 6 and C-reactive protein levels with mortality in the elderly. The American journal of medicine. 1999;106(5):506-12.

27. Ferrucci L, Corsi A, Lauretani F, Bandinelli S, Bartali B, Taub DD, et al. The origins of agerelated proinflammatory state. Blood. 2005;105(6):2294-9.

28. Beharka AA, Meydani M, Wu D, Leka LS, Meydani A, Meydani SN. Interleukin-6 Production Does Not Increase With Age. The Journals of Gerontology. 2001; 56 (2): B81-B88

29. Said EA, Al-Reesi I, Al-Shizawi N, Jaju S, AlBalushi MS, Koh CY, et al. Defining IL-6 levels in healthy individuals: A meta-analysis. Journal of Medical Virology. 2021;93(6):3915-24.

30. Huang XZ, Zhuang JH, Ren YG, Zhou LJ, Zhou Q. Association of interleukin-6 and interleukin-18 gene polymorphism with rheumatoid arthritis in Guangdong Han population. Journal of Southern Medical University. 2007;27(11):1661-4.

31. Pascual M, Nieto A, Mataran L, Balsa A, Pascual-Salcedo D, Martin J. IL-6 promoter polymorphisms in rheumatoid arthritis. Genes Immun 2000;1(5):338-40.

32. Dar SA, Haque S, Mandal RK, Singh T, Wahid $M$, Jawed $A$, et al. Interleukin-6-174G> C (rs1800795) polymorphism distribution and its association with rheumatoid arthritis: a case- control study and meta-analysis. Autoimmunity. 2017;50(3):158-69.

33. Fabris M, Quartuccio L, Lombardi S, Saracco M, Atzeni F, Carletto $A$, et al. The CC homozygosis of the $174 \mathrm{G}>\mathrm{C}$ IL-6 polymorphism predicts a lower efficacy of rituximab therapy in rheumatoid arthritis. Autoimmun Rev. 2012;11(5):315-20.

34. Hamed RM, Mohamed SA, Dwedar RA, Elkholy YS, Elgengehy FT. Association of interleukin-6 and its-174G/C promoter polymorphism with clinical and laboratory characteristics of non hepatitis $\mathrm{C}$ virus rheumatoid arthritis patients. Egyptian Journal of Medical Human Genetics. 2018;19(3):235-40.

35. Chung SJ, Kwon YJ, Park MC, Park YB, Lee SK. The correlation between increased serum concentrations of interleukin- 6 family cytokines and disease activity in rheumatoid arthritis patients. Yonsei medical journal. 2011;52(1):113-20. 